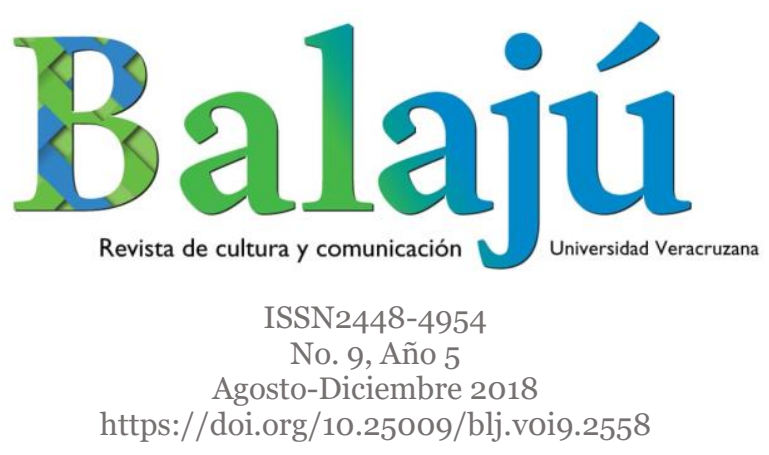

\title{
“Imágenes dantescas". Fotoperiodismo sobre feminicidios en Veracruz
}

\section{"Dantesque imagery". Photojournalism about femicide in Veracruz}

\author{
Estela Casados González 1 \\ https://orcid.org/0000-0003-0210-7410
}

RESUMEN: Los medios de comunicación construyen opinión pública en torno a la violencia hacia las mujeres. A su vez, son reflejo de la permisividad, tolerancia y naturalización con la que la sociedad aborda temas como el feminicidio. El objetivo de este documento es centrarnos en el manejo que se hace desde el fotoperiodismo sobre los asesinatos de mujeres. El uso de la imagen y la narrativa gráfica de los hechos nos ofrece una veta de interés a partir de la cual se analizan los mecanismos que reivindican la identidad de género tradicional y la sujeción patriarcal que se cierne sobre ella.

PALABRAS CLAVE: Comunicación, feminicidio, fotoperiodismo, violencia, violencia de género

ABSTRACT: The media forms public opinion regarding violence against women. In a way,
it can also be a reflection of permissiveness, tolerance and naturalization with which society
addresses issues such as femicide. The main purpose of this document is to analyze how
photojournalism reflects the murders of women. The use of image and graphic narrative
gives us a standpoint for the analysis of the mechanisms that defend a traditional gender
identity and its subjection to patriarchy.

KEYWORDS: Femicide, gender violence, media, photojournalism.

${ }^{1}$ Facultad de Antropología, Universidad Veracruzana. Correo electrónico: ecasados@uv.mx Fecha de recepción: 07/10/2018. Aceptado: 30/01/2019 


\section{"Imágenes dantescas". Fotoperiodismo sobre feminicidios en Veracruz}

Los medios de comunicación son poderosos conductores de imágenes y perfiles humanos, tienen repercusión y crean opinión pública; pero también pueden generar reacciones negativas, de rechazo e indiferencia. (CIMAC 2011, 40).

Desde 2014, quienes participamos en el proyecto Aesinatos de mujeres por razón de género. Feminicidios en la entidad veracruzana, ${ }^{2}$ enfrentamos la experiencia nada grata de registrar lo que los medios de comunicación informan sobre las violencias de las que son objeto las veracruzanas: agresiones, 3 desaparición, homicidio y feminicidio. 4

Ante la ausencia de información oficial y oportuna por parte de la Fiscalía General del Estado y de la Fiscalía Coordinadora Especializada en Investigación de Delitos de Violencia contra la Familia, Mujeres, Niñas y Niños y de Trata de Personas que ofrezca un panorama cierto sobre la violencia de género en la entidad, el objetivo principal del proyecto mencionado ha sido construir un banco de datos que permita documentar y evidenciar la situación.

Es pertinente señalar que nuestra pretensión inicial fue rebasaba al poco tiempo de haber echado a andar esta tarea. De 2014 a la fecha, la revisión exhaustiva de cuarenta y un medios de comunicación veracruzanos (portales informativos locales y periódicos impresos), 5 entre 2014 y 2016, nos encaró con un fenómeno que se desborda en un registro, en un sólo abordaje teórico y conceptual. Dado lo anterior, observamos y documentamos los casos tomando en consideración una serie de elementos que permitieran no quedarnos rezagadas ante la abundante información que ofrecen los medios de comunicación.

Una sola nota periodística, las fotos que registran los hechos de violencia contra mujeres, la narración de la actuación de las autoridades y las agresiones cada vez más crudas perpetradas por los atacantes, se traducen en diversos tipos de violencia que las víctimas experimentan simultáneamente y que como investigadoras podemos observar, analizar y denunciar.

Por ejemplo, durante el proceso de registro a partir del monitoreo, ha llamado la atención un patrón constante utilizado en diversas notas informativas que refieren los sucesos de violencia en donde las víctimas son mujeres. La manera en que se relatan las historias evidencia valoraciones que poco o nada tienen que ver con el manejo objetivo de la noticia. Al contrario, recrean y fortalecen el discurso de género predominante al revictimizar, justificar las agresiones sufridas culpabilizando a las

\footnotetext{
${ }^{2}$ Se desarrolla en la Licenciatura en Antropología Social de la Facultad de Antropología de la Universidad Veracruzana (FAUV).

3 Es decir, los tipos y modalidades de violencia, de acuerdo con lo establecido en la Ley de Acceso de las Mujeres a una Vida Libre de Violencia para el estado de Veracruz de Ignacio de la Llave.

4 Éste último según la reforma al Código Penal de Veracruz, implementada el 23 de agosto de 2011, para tipificar el delito de feminicidio.

5 Consulte el Anexo para conocer los medios utilizados.
} 
víctimas y naturalizar la violencia a través de estrategias discursivas que banalizan y ridiculizan los hechos.

El objetivo de este documento es enfocarnos en el tratamiento que se hace desde el fotoperiodismo sobre los asesinatos de mujeres. El uso de la imagen y la narrativa gráfica de los acontecimientos ofrecen una veta de interés a partir de la cual podemos analizar los mecanismos que reivindican la identidad de género tradicional y la sujeción patriarcal que se cierne sobre ella.

Con este propósito, en la primera parte del documento se expondrá el enfoque que es referente para el análisis que se presenta en las siguientes páginas. Posteriormente, se delimita el significado, utilización y pertinencia de un concepto clave como lo es feminicidio, para después dirigir nuestra atención al proceso con el que el fotoperiodismo local construye gráficamente las noticias sobre asesinatos de mujeres.

Para la realización de este texto parto de la teoría feminista. Ello guarda implicaciones éticas y metodológicas en el proceso de sistematización y análisis de la información gráfica. Un principio básico de la ética feminista es no revictimizar a las mujeres; en todo caso, se les sitúa como un sujeto en un entramado de relaciones sociales que parten de la construcción sexogenérica de la persona. Es por ello que no se incluyen las fotografías de las que se hace referencia en la tercera parte de este artículo. Esta estrategia entraña el reto de analizar imágenes que, aunque se describen, están ausentes.

\section{La invisibilidad de las mujeres, la visibilidad de los prejuicios. Análisis crítico de la imagen}

Lo que convierte en extraordinario el rol de los medios de comunicación es su papel de creadores de realidad, pues es muy difícil determinar cuál es la diferencia entre la propia realidad y la realidad "reconstruida" por los medios. (García, et al. 2003. En Bustos 2011, 34).

Alicia Puleo señala que en el mundo de la comunicación un buen conocimiento del concepto género permite comprender y actuar con sentido crítico e innovador. Así, la interpretación de cualquier imagen debe ser hecha desde la perspectiva de las teorías de la construcción social del género (Puleo 2007, 14).

Hay que recordar que fue a partir de los Estudios de la mujer que se elaboró la primera formulación centrada en la caracterización de la subordinación de la población femenina; pero fue gracias a los estudios sobre las mujeres que se han realizado investigaciones enfocadas en la comparación de las condiciones de mujeres y varones, así como al interior del conjunto de las mujeres.

Concretamente, los estudios de género enfatizan aspectos específicos de construcción social y su carácter relacional. Por ello, la categoría género es la idónea para el análisis de esta dimensión específica de la desigualdad social que se articula con otras, tales como la étnica y la de clase. Es así como los estudios feministas ponen énfasis en la voluntad política que subyace al análisis, para la superación de la desigualdad en razón de los géneros (De Barbieri 2000, 103). 
Tal como señala Elsa Muñiz, género, en tanto categoría analítica,

[...] abrió posibilidades enteramente nuevas sobre la naturaleza de la investigación científica. Combinando la teoría feminista con los desarrollos contemporáneos de la historia, la filosofía, de la ciencia y la sociología, se añadió una nueva dimensión al análisis, se otorgó importancia a los cuestionamientos acerca del contenido y práctica de la ciencia y de la interacción con el resto del mundo natural que los científicos han cultivado históricamente, así como de las metas que tradicionalmente han sido idealizadas en las ciencias naturales. La crítica feminista de la ciencia ha argumentado que la ciencia moderna parte de una estructuración conceptual del mundo que contiene una particular y específica ideología de género en la que se establece una histórica relación entre los ideales que la cultura ha otorgado a la masculinidad y las convencionales concepciones sobre el conocimiento y la razón, así como los ideales de la feminidad vinculados al cuidado y la naturaleza, o mejor dicho, al desconocimiento y a la sinrazón [...] (Muñiz 2013, 4).

La historiadora estadounidense Joan W. Scott parte de la idea de que género es una categoría analítica que deposita su mirada crítica en las relaciones basadas en las diferencias que distinguen a los sexos. Estas relaciones constituyen una forma primaria de relaciones significantes de poder $(1999,61)$.

Desde dicha categoría hay un cuestionamiento central a la tradición de la ciencia moderna que se sustenta en dicotomías o binarismos, tales como la oposición entre sujeto y objeto, femenino-masculino, público-privado, cuerpo-mente, naturaleza-cultura. En vez de ello, se propone una filosofía encarnada y un conocimiento social, temporal y espacialmente situado (Haraway en Muñiz 2013, 4).

Scott agrega en su definición sobre género que éste se encuentra integrado por cuatro elementos interrelacionados entre sí (Scott 1999, 61-63):

a) Símbolos culturalmente disponibles que evocan representaciones múltiples y contradictorias.

b) Conceptos normativos que manifiestan, limitan y contienen las posibilidades metafóricas de los símbolos.

c) Nociones políticas y referencias a las instituciones y organizaciones sociales.

d) Identidad subjetiva

Los dos primeros hacen alusión a aquellos contenidos socioculturales que encontramos en los símbolos, las instituciones y organizaciones desde donde se abordan temas, así como los problemas que aluden a una valoración y consideración desigual de éstos. Sin que necesariamente se haga referencia a personas concretas y sexuadas, Scott parte de una percepción que integra distintos niveles de la realidad social para aprehender y tener una visión más compleja y completa de ella. No se 
reduce al análisis de individuos, sino que parte de la complejidad social en espacio y tiempo para analizar y comprender las identidades genéricas en el entramado social.

A partir de ello, por ejemplo, nos es posible observar que en el espacio público se establecen referentes discursivos que alimentan y recrean la conformación de las identidades de género tradicionales. Es a través de instituciones como la iglesia, la universidad o la política que se propagan y legitiman estos mandatos de género que determinan cómo ser hombre o cómo ser mujer y el papel que cada uno de ellos debe desarrollar.

Se aprueban comportamientos y actividades, pero también se sancionan a través de estereotipos que fijan modelos rígidos de masculinidad y feminidad. Forman parte del mundo de lo simbólico junto a los diversos discursos de legitimación de la estratificación (Puleo 2007, 24). Las normas y sanciones de género funcionan como un refuerzo de la identidad y el estatus de género; muchas de ellas afectan a la sexualidad, por lo que no nos sorprende que exista un control universal de la sexualidad femenina (Puleo, 25).

Los medios de comunicación son un vehículo idóneo para validar y fortalecer estas normas y sanciones de las que nos advierte Alicia Puleo. Diversos estudios sobre género y comunicación (Bach, et al. 2000; De los Ríos y Martínez 1997; Lagunes 2009; De Fontcuberta 1994) han dado cuenta del papel que se les asigna a las mujeres en esos espacios: podemos encontrarlas como parte de los medios informativos o como objeto de las notas periodísticas. Ambas esferas nos devuelven la imagen de subordinación, invisibilización y sujeción con la que son vistas en prácticamente todo el planeta.

Para aquéllas que laboran en los medios informativos, a pesar de que estén frente a un micrófono, como es el caso de las conductoras de programas radiofónicos y televisivos, continúan siendo invisibilizadas a partir del papel decorativo que se les asigna y del porcentaje menor que ocupan como lectoras de noticias (CIMAC, 2011).

Por otra parte, cuando son objeto de la nota periodística, es frecuente que la historia sea narrada a partir de los clichés frecuentes que las rodean. Se fortalece la dicotomía buena mujer/mala mujer. Las narraciones e imágenes que conforman esta estrategia discursiva son clara muestra de ello; así es como se va tejiendo finamente el discurso de sujeción y opresión que fortalece la construcción de una identidad femenina tradicional, la cual es validada por el entorno misógino y patriarcal.

Es a partir de esta idea que retomo a Teun van Dijk (1997) y su propuesta del análisis crítico del discurso. El autor expone que

En los objetivos descriptivos, explicativos y prácticos de los estudios del ACD [Análisis Crítico del Discurso] radica un esfuerzo para descubrir, revelar o divulgar aquello que es implícito, que está escondido o que por algún motivo no es inmediatamente obvio en las relaciones de dominación discursiva o de sus ideologías subyacentes. El ACD se centra específicamente en las estrategias de manipulación, legitimización, creación de consenso y otros mecanismos discursivos que influyen en el pensamiento (e indirectamente en las acciones) en beneficio de los más poderosos (Van Dijk, 17). 
$\mathrm{Al}$ analizar críticamente el discurso expuesto por el fotoperiodismo cuando reporta casos de feminicidio, describimos y analizamos las imágenes que reproducen y validan la sujeción del discurso de género hegemónico. Tal como lo señala De Barbieri (2000), es a partir de la perspectiva feminista que hay un posicionamiento crítico y político ante ello. Parafraseando a Van Dijk (1997), descubrir, revelar y denunciar, permiten hacer evidente lo que ha sido normalizado y, por tanto, invisibilizado: la violencia que desde los medios de comunicación, vía el fotoperiodismo, revictimiza a aquellas que han sido privadas de la vida.

Las fotografías del feminicidio no sólo hablan de quién domina sino también de quién o quiénes pueden permanecer en el olvido, en un sistema que no garantiza el derecho ni el respeto a la vida. Habría que preguntarnos hasta qué punto puede haber neutralidad en la visión [...]. Nuestros miedos, nuestros deseos, pero también nuestras aversiones se moldean por las imágenes a las que estamos expuestos (Berlanga 2018, 24-25).

En las siguientes páginas se analiza la manera en que algunos medios informativos veracruzanos manejan la imagen de las mujeres que son víctimas de asesinatos violentos, concretamente de feminicidio.

\section{¿Feminicidio u homicidio?}

El término feminicidio es un anglicismo que data de 1801. Fue utilizado por primera vez en $A$ satirical view of London at the commencement of the nineteenth century. John Corry, autor de dicha obra, utilizó la palabra femicide para denominar el "asesinato de una mujer" (Russel y Harmes 2006, 75). En 1990, Diana Russell y Jane Caputi retomaron el término y lo enriquecieron al definirlo como "el asesinato de mujeres realizado por hombres motivado por odio, desprecio, placer o un sentido de propiedad de las mujeres" (Russel y Harmes, 77).

En la primera década del siglo XXI, la antropóloga mexicana Marcela Lagarde y de los Ríos atrajo el término anglosajón como una herramienta que permitiría analizar y visibilizar los asesinatos de mujeres en Ciudad Juárez, Chihuahua, que se replicaban velozmente a lo largo y ancho del país. No hay que perder de vista la resignificación que le dio la autora al deconstruir este concepto para el ámbito latinoamericano y, concretamente, el mexicano:

[El feminicidio] no se trata sólo de la descripción de crímenes que cometen homicidas contra niñas y mujeres, sino de la construcción social de estos crímenes de odio, acumulación de la violencia de género contra las mujeres, así como la impunidad que los configura [...] el feminicidio es un crimen de Estado, ya [que] éste no es capaz de garantizar la vida y la seguridad de las mujeres en general, quienes vivimos diversas formas y grados de violencia cotidiana a lo largo de la vida (Rusel y Harmes, 12).

A diferencia de otras regiones de América Latina en donde se utiliza el término femicidio, en México se utiliza la voz feminicidio. Lagarde expone que este último es una voz homóloga a homicidio que permite denominar los crímenes de lesa 
humanidad que contienen las violaciones, los secuestros y las desapariciones de niñas y mujeres en un cuadro de colapso institucional.

La Ley General de Acceso de las Mujeres a una Vida Libre de Violencia (LGAMVLV) fue publicada en el Diario Oficial de la Federación el 1 de febrero de 2007. Constituyó la primera vez que el Estado mexicano hacía referencia al término feminicidio. Gabriela Atencio (2015) expone que ese mismo año, el lingüista y miembro de la Academia Mexicana de la Lengua, Carlos Montemayor, solicitó la incorporación de la palabra referida al Diccionario de la Real Academia Española (DRAE):

Homicidio proviene del latín homicidium, cuya radical inicial proviene del nominativo de homo, hombre, cuyo genitivo es hominis, que presenta un alargamiento silábico. Homicidio se forma, pues, con el radical abreviado hom(-o). Feminicidio, por su parte, tiene como radical inicial el nominativo fémina, mujer, cuyo genitivo es feminae, que no presenta alargamiento silábico. Por tanto, se forma a partir del radical fémin(-a). Sería incorrecto querer componer la voz a partir del acortamiento fém(ina), para decir femicidio, puesto que no deriva de la palabra francesa femme (cuyo acortamiento sería fem[me]), sino del latín femina, voz que sigue teniendo el mismo valor en la lengua española. De fémina y del genitivo feminae se deriva correctamente, pues, feminicidio (Montemayor en Atencio 2015, 21-22).

En México, bajo el cobijo e impulso del crimen organizado, el asesinato de mujeres por razones de género va en aumento. Diariamente siete mexicanas son víctimas de feminicidio. ${ }^{6}$ A pesar de que el país cuenta con leyes que permitirían revertir la situación, así como mecanismos legales para proteger la vida de las ciudadanas, la tendencia no ha cambiado. Las cifras oficiales que documentan la violencia contra niñas y mujeres no están actualizadas o no se dan a conocer.

$\mathrm{Y}$, a todo esto, ¿qué es un feminicidio y qué no lo es? A partir de la reforma al Código penal del estado de Veracruz, realizada el 11 de julio de 2012, se establece el tipo penal de feminicidio. El artículo 367 Bis dispone que comete este ilícito "[...] quien por razones de género priva de la vida a una mujer" (Gobierno del Estado de Veracruz 2012, 48). Dichas razones de género son las manifestaciones de discriminación y odio a las mujeres a través de las cuales se materializa el feminicidio, lo que permite diferenciarlo de un homicidio doloso (Gobierno...).

El Código Penal de Veracruz establece que para que los asesinatos de mujeres sean considerados como feminicidios, deben presentar al menos alguna de las siguientes razones de género:

1. Que exista o haya existido una relación entre el activo y la víctima, una relación de parentesco por consanguinidad o afinidad, de

\footnotetext{
${ }^{6}$ Estudios alternos, tales como el de María Salguero indican que son nueve las mexicanas que son asesinadas diariamente. De acuerdo con el proyecto universitario desarrollado en la FAUV, en promedio quince mujeres fueron asesinadas mensualmente en el estado de Veracruz durante el primer semestre de 2018. Es decir, una cada tercer día.
} 
matrimonio, concubinato, noviazgo o cualquier otra relación de hecho o amistad.

2. Que exista o haya existido una relación laboral, escolar o que implique confianza, subordinación o superioridad, entre el activo y la víctima.

3. Que la víctima presente signos de violencia sexual de cualquier tipo. 4. Que presente lesiones infamantes, degradantes o mutilaciones previas a la muerte, o marcas infamantes, degradantes o mutilaciones sobre el cadáver.

5. Que hayan existido amenazas, acoso o lesiones del sujeto activo en contra de la víctima.

6. Que el cuerpo de la víctima sea expuesto o arrojado en un lugar público.

7. Que la víctima haya sido incomunicada (Gobierno...).

No todos los asesinatos de mujeres son catalogados como feminicidios, ya sea porque no cumplen con las características antes enunciadas o porque no se pueden comprobar ninguna de ellas, porque la autoridad competente no tiene la capacitación ni el equipo especializado.

Lo cierto es que los asesinatos de mujeres y niñas en el estado de Veracruz se han incrementado en los últimos años y la tendencia se mantiene. De 2011 a 2013 se contabilizó un promedio de ocho feminicidios al mes en la entidad. En 2012, noventa y cinco veracruzanas fueron víctimas de feminicidio y, en 2013, noventa y dos mujeres perdieron la vida a manos de sus agresores (CIDEM s/f).

Datos recabados por el proyecto Asesinatos de mujeres y niñas por razón de género. Feminicidios en la entidad veracruzana, establecen que en 2014 tuvieron lugar setenta y cuatro feminicidios y, en 2015, fueron noventa y nueve. En 2016, se registraron ciento noventa asesinatos de mujeres en la entidad, de los cuales la descripción de los hechos define a ciento cuarenta y dos de ellos como feminicidios. Octubre fue el mes con más asesinatos de mujeres en la entidad. Se reportaron treinta. 7

Tal como lo reporta la Tabla 1. "Municipios veracruzanos con asesinatos de mujeres en 2016", de los 212 municipios que conforman la entidad, en donde se registraron los más altos números de asesinatos de mujeres fueron los siguientes:

\footnotetext{
7 Los hechos tuvieron lugar en veinte municipios veracruzanos: Pánuco, Poza Rica, Huiloapan de Cuauhtémoc, Camarón de Tejeda, Emiliano Zapata, Hueyapan de Ocampo, Xalapa, Córdoba, Carrillo Puerto, Comapa, Catemaco, Acayucan, Minatitlán, San Andrés Tuxtla, Ciudad Isla, Moloacán, Las Choapas, Soteapan, Jáltipan y Coatzacoalcos.
} 
Tabla 1. Municipios veracruzanos con asesinatos de mujeres en 2016

\begin{tabular}{|r|l|c|c|c|}
\hline \multicolumn{5}{|l|}{$\mathbf{5 1 6}$} \\
\hline$\#$ & Municipio & Feminicidio & Homicidio & Total \\
\hline 1 & Xalapa & 5 & 6 & 11 \\
\hline 2 & Veracruz & 5 & 3 & 8 \\
\hline 3 & Córdoba & 0 & 6 & 6 \\
\hline 4 & Tihuatlán & 5 & 0 & 5 \\
\hline 5 & Papantla & 5 & 0 & 5 \\
\hline 6 & San Andrés Tuxtla & 4 & 0 & 4 \\
\hline 7 & Orizaba & 0 & 3 & 3 \\
\hline 8 & Gutiérrez Zamora & 0 & 2 & 2 \\
\hline
\end{tabular}

Fuente: Proyecto Asesinatos de mujeres y niñas por razón de género.

Feminicidios en la entidad veracruzana. Facultad de Antropología, Universidad Veracruzana.

El número de asesinatos de mujeres rebasa por mucho la cifra que cada año se había dado a partir de este lamentable fenómeno. El espacio de transición que tuvo lugar en la recta final de 2016, entre un gobernador con licencia, otro nombrado para ser interino y uno más que gobernaría por dos años, se caracterizó por el estado de emergencia que aún vive la entidad. Parafraseando a la antropóloga Rita Segato, en Veracruz el termómetro de la violencia social se depositó en el cuerpo de las mujeres. ${ }^{8}$

Pese a la gravedad de la situación, el tema fue ignorado en las agendas de los gobiernos saliente y entrante. No así para aquellos medios informativos que en el mes de octubre de 2016 mostraron imágenes de los cuerpos sin vida, víctimas de feminicidio.

Lamentablemente en 2017 aumentó el número de veracruzanas asesinadas. La crisis humanitaria y financiera que vive la entidad constituyó uno de los motivos principales por los que el Partido Revolucionario Institucional (PRI) fue removido del palacio de gobierno estatal como resultado de la contienda electoral para elegir a un nuevo gobernador, llevada a cabo el 5 de junio de 2016.

Pese al compromiso de campaña de brindar seguridad a la población de la entidad hecho por la coalición "Unidos para rescatar a Veracruz", conformada por el PAN-PRD, 9 los asesinatos en suelo veracruzano incrementaron y la vulneración a la seguridad de quienes habitan la entidad adereza la zozobra de todos los días.

Las mujeres que habitan la entidad y conforman más de la mitad de la población estatal, ${ }^{10}$ han padecido este recrudecimiento. De acuerdo con lo publicado por los medios de comunicación locales, tan sólo en el primer año de transición partidista, doscientas cuarenta y ocho veracruzanas fueron asesinadas. Ciento setenta y seis de estos hechos presentaron las razones de género para ser considerados como feminicidios.

\footnotetext{
${ }^{8}$ Comunicación personal, 14 de octubre de 2016. Santiago de Querétaro, Querétaro.

9 Partido Acción Nacional (PAN) y Partido de la Revolución Democrática (PRD).

${ }^{10}$ En Veracruz hay 8, 112505 habitantes. 4, 203365 son mujeres.
} 
Tabla 2. Municipios veracruzanos con asesinatos de mujeres en 2017

\begin{tabular}{|c|c|c|c|c|}
\hline \multicolumn{5}{|c|}{2017} \\
\hline$\#$ & Municipio & Feminicidio & Homicidio & Total \\
\hline 1 & Coatzacoalcos & 13 & 13 & 26 \\
\hline 2 & Córdoba & 7 & 9 & 16 \\
\hline 3 & Minatitlán & 10 & 5 & 15 \\
\hline 4 & Poza Rica & 9 & 4 & 13 \\
\hline 5 & Xalapa & 9 & 3 & 12 \\
\hline 6 & Veracruz & 8 & 0 & 8 \\
\hline 7 & Ixtaczoquitlán & 6 & 0 & 6 \\
\hline 8 & Tuxpan & 4 & 0 & 4 \\
\hline
\end{tabular}

Fuente: Proyecto Asesinatos de mujeres y niñas por razón de género. Feminicidios en la entidad veracruzana. Facultad de Antropología, Universidad Veracruzana.

Los asesinatos de mujeres se presentaron a lo largo y ancho de la entidad, tal como lo muestra la Tabla 2. "Municipios veracruzanos con asesinatos de mujeres en 2017". Poza Rica y Tuxpan en la región norte; Córdoba, Ixtaczoquitlán, Xalapa y Veracruz, en la región centro; Minatitlán y Coatzacoalcos, en el sur. Ya sea en los principales centros urbanos, en la costa, la montaña o en los municipios de composición rural, están ocurriendo este tipo de crímenes.

En 2017, junio fue el mes más violento. Treinta y una ciudadanas fueron asesinadas. De estos casos, veinte cumplen con las características para ser considerados como feminicidios. En su mayoría, se desconoce quién fue el agresor, ya que los cuerpos fueron encontrados en la vía pública o en sus domicilios sin que se sepa cómo ocurrieron los hechos.

De acuerdo con los datos recabados por el proyecto universitario, se reportó que cada tercer día una mujer "desaparecía" mientras se desplazaba a su casa, a la escuela o al trabajo, sin importar la hora, si era de día o de noche. Aunado a ello, los medios de comunicación dieron cuenta de sesenta y dos reportes de agresiones contra veracruzanas, es decir, dos mujeres cada día eran objeto de violencia.

¿Cómo reportan los medios estos hechos, sobre todo en los casos de feminicidio y homicidios de mujeres? ¿Cómo son presentados los cuerpos de aquellas que perdieron la vida a partir de un evento violento?

\section{Imágenes que tienen género}

Resulta imposible hacer buen periodismo sin cuestionarse persistentemente cómo hemos construido nuestra idea del mundo, y qué tamiz utilizamos para describirlo ante nuestro auditorio, ya sea de prensa escrita o de medios electrónicos.

Lydia Cacho

(CIMAC 2011, 2) 
Dentro de los objetivos estratégicos y medidas de la Plataforma de Acción de Beijín o Cuarta Conferencia Mundial sobre la Mujer, se plantea que los Estados que suscribieron están obligados a cumplir sus recomendaciones. Algunas de éstas se encuentran enfocadas en procurar el manejo respetuoso e igualitario de la imagen de las mujeres en los medios.

Dicha Plataforma de acción lo establece en el capítulo J:

Debería potenciarse el papel de la mujer mejorando sus conocimientos teóricos y prácticos y su acceso a la tecnología de la información, lo que aumentará su capacidad de luchar contra las imágenes negativas que de ella se ofrecen a escala internacional y de oponerse a los abusos de poder de una industria cada vez más importante [...] Fomentar una imagen equilibrada y no estereotipada de la mujer en los medios de difusión [...] Alentar a los medios de difusión a que se abstengan de presentar a la mujer como un ser inferior y explotarla como objeto sexual y bien de consumo, en lugar de presentarla como un ser humano creativo, agente principal, contribuyente y beneficiaria del proceso de desarrollo (ONU 1995, 108, 110, 111).

Pese a que el Estado mexicano es firmante de estos acuerdos, en los hechos poco o nada ha logrado para hacer realidad esta plataforma. Los medios de comunicación sólo son guiados por su línea editorial, cuando la tienen, sin guardar respeto alguno por su audiencia.

Tal como se señala en el texto Hacia la construcción de un periodismo no sexista,

los medios de comunicación siguen situados en la dicotomía de mujeres buenas y malas, víctimas y victimarias, no importa qué papel o rol ocupen [...] la lógica es la misma, se les mira desde lo que tradicionalmente se le ha atribuido a lo femenino: sensibilidad, cariño, cuidado de otros y buena presentación (CIMAC 2011, 36).

En el banco de imágenes que ha generado el proyecto Asesinatos de mujeres por razón de género. Feminicidios en la entidad veracruzana, encontramos que las fotografías exhibidas, sin excepción, reflejan el horror, salvajismo e impunidad con el que las veracruzanas son asesinadas. Muestran hechos por demás fuertes y dolorosos, pero es el uso de la escena a través de la lente, lo que llama nuestra atención. Hay una intención fotográfica de quien maneja la cámara que expresa con contundencia la brutalidad del hecho, pero también el despojo del último atisbo de dignidad que una mujer puede tener después de muerta.

Portales informativos veracruzanos, a la par de periódicos regionales, muestran estas imágenes. Si bien hay un importante decremento en su uso por parte de los medios que refieren estas notas, aquellos que aún las utilizan se destacan por la crudeza de la información que exhiben.

Para efectos de este documento me enfocaré en dos medios de comunicación. Uno de ellos es el periódico La Opinión, cuya cobertura alcanza la zona norte del 
estado de Veracruz. En sus publicaciones hace referencia a los municipios de Poza Rica, Cazones, Tihuatlán, Castillo de Teayo, Papantla, Gutiérrez Zamora, Tecolutla, San Rafael, Tlapacoyan, Martínez de la Torre, Tuxpan, Tamiahua, Naranjos, Ozuluama, Cerro Azul, Tancoco y Álamo. Este medio, muy popular entre sus lectores, cuenta con un tiraje que abarca los municipios mencionados, así como parte del estado de Puebla.

El segundo es el portal informativo El Piñero de la Cuenca. La información que publica se concentra en la llamada Cuenca del Papaloapan, concretamente en los municipios de Tierra Blanca, Cosamaloapan, Veracruz, la región de Los Tuxtlas y el estado de Oaxaca. Al ser un medio que se consulta vía internet, su cobertura trasciende el ámbito geográfico en donde se generan las noticias que reporta. Es ampliamente consultado en la zona centro y sur del estado de Veracruz.

Para el análisis que se presenta a continuación se escogieron tres notas que hacen referencia a dos feminicidios y al homicidio de una mujer. La elección de éstas se debe a que las imágenes que muestran los cuerpos de las víctimas son el vehículo principal del discurso informativo, tal como se describirá más adelante. En respeto a las mujeres que son exhibidas en las fotografías, no se incluye referencia a su identidad, ni del municipio y fecha en donde fueron localizadas. Tampoco se incluyen las imágenes que hacen alusión a ellas, sólo se describen para efectos del análisis. Únicamente se comparten los nombres de los medios en donde fue publicada la información de los casos.

\section{Discurso periodístico: imagen del odio hacia las mujeres}

La fotografía es un medio de expresión poderoso. Debidamente empleada, es un gran poder para nuestro mejoramiento e inteligencia; mal empleada, puede encender muchos fuegos inoportunos. El fotoperiodismo, debido al enorme público al alcance de las publicaciones que lo usan, influye más sobre el pensamiento y la opinión del público que ninguna otra rama de la fotografía. Por estas razones es importante que el fotoperiodista posea (además de la maestría esencial de sus herramientas) un fuerte sentido de integridad y la inteligencia necesaria para poder entender y presentar un tema correctamente (Smith 2004, 209).

Nota 1. Publicada en el periódico La Opinión, bajo el título "Empleado municipal iestranguló a su mujer y se ahorcó! [en] El Salón de belleza [...] fue asesinada la estilista por su celoso esposo. La asfixió con un pañuelo y después en su parcela se colgó en un árbol”.

La composición de tres fotografías a color ocupa el lugar central de la nota informativa. Una de las imágenes exhibe a una mujer sin vida que yace en el suelo. Viste pantalón "capri” que deja entrever su ropa interior negra, porta una blusa sin mangas, la cual se encuentra levantada dejando ver su torso desnudo hasta la altura del busto.

En su cuello se alcanza a distinguir un pañuelo bicolor. El rostro femenino está ennegrecido por efectos de la estrangulación y el paso de las horas desde que 
aconteció el feminicidio. Sus rasgos faciales no se distinguen con claridad en la fotografía; uno de sus brazos descansa en su abdomen, el otro está en el suelo. Sus piernas se muestran abiertas. Su cabellera está revuelta. Junto a ella está un bolso y la base de algunos pedestales de lo que parece ser un ventilador y una silla.

Otra imagen de la misma nota muestra a un sujeto "en pie", sostenido por una soga que pende de un árbol. Los ojos y la boca cerrados. La cabeza echada hacia un lado. Los brazos descansan a los costados de su cuerpo, las manos permanecen entrecerradas. Piernas ligeramente separadas que dan el efecto visual de que él está de pie, ya que la fotografía sólo lo muestra hasta las rodillas. Porta camisa deportiva, pantalón con cinturón y camisola. Su ropa luce ordenada e intacta, bien acomodada y cubre la totalidad de su cuerpo con excepción de las manos, cuello y rostro. En la fotografía, que fue tomada de noche, se ven algunos arbustos al fondo.

La tercera imagen de esta nota resulta ser una foto más pequeña que se encuentra en medio de las dos anteriores y que, de cierta forma, las enlaza. La manera en que fueron distribuidas en la página simula un rompecabezas que logra unirse gracias a esta última foto. Muestra a dos hombres cargando un cuerpo cubierto con lo que parece ser una manta. Atrás de ellos hay otros dos que ayudan a cargar el cadáver que llevan en alto.

Nota 2. Publicada en el periódico La Opinión, bajo el título "Todavía no identifican a la mujer asesinada. Presentó varios golpes en diversas partes del cuerpo. Podría ir a la fosa común".

Es una nota breve que presenta dos imágenes en blanco y negro. Evidencian el hallazgo de una víctima de feminicidio. Se le ha dado mayor espacio a la fotografía en donde se muestra el torso de una mujer que tiene el rostro desfigurado y, por tanto, irreconocible. Porta una blusa oscura, la cual está levantada hasta la altura de los senos. Los brazos abiertos y extendidos completamente. La publicación refiere que el cuerpo estaba en estado de "putrefacción” y hace una descripción exhaustiva sobre la ropa interior de la víctima: "estaba boca arriba con las piernas fracturadas y vestía ropa interior negra, brasiere estampado rosa y blusa negra”. Se reitera lo que la imagen muestra.

En la otra gráfica que acompaña esta información destacan a elementos policiacos que acudieron al lugar. Tres hombres, uno de ellos vestido de policía, que toman nota y platican entre ellos. Están de pie y en grupo. Sus ropas y uniformes cubren la totalidad de sus cuerpos con excepción de manos, cara y cuello.

Indagando sobre este caso, encontramos una nota posterior que da seguimiento a la noticia. Se retoma el título que identifica al caso y a la víctima como mujer asesinada. Ilustra una foto del cadáver en la misma postura descrita anteriormente. Sin embargo, en esta oportunidad la imagen muestra al cuerpo completo con el torso inferior semidesnudo. Yace con las piernas abiertas, mientras cuatro personas que están de pie la observan detenidamente. Depositan su atención en el rostro desfigurado que es la parte más perturbadora del cadáver. 
Nota 3. Publicada en el portal informativo El Piñero de la Cuenca, con el titular "Hallan destrozado cuerpo femenino en Veracruz. Dantesco".

Una práctica recurrente de este medio es exhibir imágenes de personas fallecidas bajo circunstancias que mermaron totalmente la integridad física de los cuerpos. Al mostrar las imágenes en el portal de internet distorsionan levemente la imagen, haciéndola borrosa o sobreponiéndole letras trasparentes (marcas de agua), lo cual no es de mucha utilidad porque transparenta el estado que guarda el cadáver y aumenta la curiosidad de quien ve las publicaciones. "Imágenes dantescas" es una frase sumamente socorrida y utilizada en la emisión de noticias de este portal informativo, en donde dichas fotografías ocupan el lugar central.

Las gráficas que acompañan la nota referida muestran un cuerpo femenino al cual ya no se le distingue figura humana alguna. Yace en una autopista en la noche. Se describe cómo las autoridades dieron con los restos mortales: a partir de llamadas de automovilistas, se les informó que había un cuerpo abandonado en la carpeta asfáltica de una autopista. En este caso, la información también es breve. Se destaca por la única imagen a color que acompaña a la página y que llama la atención de las y los lectores.

\section{¿La imagen de la misoginia?}

¿Qué es, en realidad, un reportaje fotográfico, un relato fotográfico? Algunas veces hay una imagen única, cuya composición posee tal vigor y riqueza, y cuyo contenido expresa tanto, que esta sola imagen es ya una historia completa en sí misma. Pero esto sucede muy raras veces. Los elementos que conjuntamente pueden hacer brillar un sujeto generalmente están dispersos -ya sea en términos de espacio o tiempo- y reunirlos a la fuerza es manipularlos, cosa que considero una trampa. Pero cuando se logra fotografiar tanto la médula como el fulgor del sujeto, esto es lo que se llamaría un relato fotográfico [...] (Cartier-Bresson 2004, 223).

Recordemos que Van Dijk (1997) en su propuesta del análisis crítico del discurso enfatiza que hay que descubrir, revelar y divulgar aquello que manipula y legitima las relaciones de dominación y sus ideologías. Es necesario realizar este ejercicio de análisis y denuncia porque la violencia permanece implícita en el quehacer cotidiano, pero también en lo que trasciende lo fugaz del instante. Trasciende porque educa y naturaliza la dominación y la violencia.

$\mathrm{Al}$ retomar las notas periodísticas descritas podemos encontrar puntos en común respecto al tratamiento que el fotoperiodismo da a las mujeres en tanto objetos, aún después de muertas, y aquello a lo que se desea clasificar como femenino. Tal como observamos en el cuadro 1. "Características de víctimas y agresores en las notas periodísticas”, hay elementos que atraviesan lo que comunican las imágenes referidas.

Tabla 3. Características de víctimas y agresores en las notas periodísticas. 


\begin{tabular}{|c|c|c|c|}
\hline Características & Nota 1 & Nota 2 & Nota 3 \\
\hline \multirow[t]{2}{*}{$\begin{array}{l}\text { Presentación de la } \\
\text { víctima/agresor }\end{array}$} & $\begin{array}{l}\text { Víctima } \\
\text { Cuerpo } \\
\text { semidesnudo } \\
\text { Cabello } \\
\text { desordenado } \\
\text { Rostro ennegrecido } \\
\text { Piernas abiertas } \\
\text { Brazos: uno de ellos } \\
\text { sobre el abdomen y } \\
\text { otro en el suelo }\end{array}$ & $\begin{array}{l}\text { Víctima } \\
\text { Cuerpo } \\
\text { semidesnudo } \\
\text { Cabello } \\
\text { desordenado } \\
\text { Rostro desfigurado } \\
\text { Cuerpo en } \\
\text { descomposición }\end{array}$ & $\begin{array}{l}\text { Víctima } \\
\text { Restos de la } \\
\text { víctima esparcidos } \\
\text { en carpeta } \\
\text { asfáltica }\end{array}$ \\
\hline & $\begin{array}{l}\text { Agresor } \\
\text { Cuerpo vestido } \\
\text { Simula estar de pie } \\
\text { Cabello ordenado } \\
\text { Cabeza echada a un } \\
\text { lado } \\
\text { Ojos y boca cerrados }\end{array}$ & $\begin{array}{l}\text { Agresor } \\
\text { No se establece ni se } \\
\text { presenta agresor } \\
\text { alguno }\end{array}$ & $\begin{array}{l}\text { Agresor } \\
\text { No se establece ni } \\
\text { se presenta } \\
\text { agresor alguno. }\end{array}$ \\
\hline $\begin{array}{l}\text { Presentación de } \\
\text { imágenes masculinas }\end{array}$ & $\begin{array}{l}\text { Agresor: De pie, } \\
\text { vistiendo } \\
\text { ordenadamente sus } \\
\text { ropas. El estado del } \\
\text { cuerpo no presenta } \\
\text { rigor mortis. } \\
\text { Exhibiendo la soga } \\
\text { alrededor de cuello. } \\
\text { Otros: Hombres } \\
\text { que cargan el cuerpo } \\
\text { del agresor. Se } \\
\text { presenta de pie y } \\
\text { con ropa de trabajo } \\
\text { perfectamente } \\
\text { ordenada. }\end{array}$ & $\begin{array}{l}\text { Agresor: No se } \\
\text { presenta } \\
\text { Otros: De pie con } \\
\text { ropa de trabajo. } \\
\text { Observan a la } \\
\text { víctima que yace en } \\
\text { el suelo }\end{array}$ & $\begin{array}{l}\text { Agresor: no se } \\
\text { presenta } \\
\text { Otros: no se } \\
\text { presenta }\end{array}$ \\
\hline $\begin{array}{l}\text { Presentación y } \\
\text { disposición del } \\
\text { cuerpo de la víctima }\end{array}$ & $\begin{array}{l}\text { En el piso de una } \\
\text { estética }\end{array}$ & En el suelo & $\begin{array}{l}\text { En la carpeta } \\
\text { asfáltica de una } \\
\text { autopista. Los } \\
\text { restos que exhibe } \\
\text { la imagen no } \\
\text { permiten } \\
\text { distinguir la figura } \\
\text { de la mujer a la } \\
\text { que se alude. Se } \\
\text { resalta lo amorfo } \\
\text { de los restos } \\
\text { corporales. Se le } \\
\text { deshumaniza }\end{array}$ \\
\hline $\begin{array}{l}\text { Presentación y } \\
\text { disposición del } \\
\text { cuerpo del agresor }\end{array}$ & $\begin{array}{l}\text { De pie. Vestimenta } \\
\text { ordenada }\end{array}$ & No se presenta & No se presenta \\
\hline Feminicidio. & $\begin{array}{l}\text { Que exista o haya } \\
\text { existido una }\end{array}$ & $\begin{array}{l}\text { Que el cuerpo de la } \\
\text { víctima sea expuesto }\end{array}$ & $\begin{array}{l}\text { Debido al estado } \\
\text { en que se encontró }\end{array}$ \\
\hline
\end{tabular}




\begin{tabular}{|c|c|c|c|}
\hline $\begin{array}{l}\text { Hipótesis que cumple } \\
\text { el caso. }\end{array}$ & \multirow[b]{2}{*}{$\begin{array}{l}\text { relación entre el } \\
\text { activo y la víctima, } \\
\text { una relación de } \\
\text { parentesco por } \\
\text { consanguinidad o } \\
\text { afinidad, de } \\
\text { matrimonio, } \\
\text { concubinato, } \\
\text { noviazgo o cualquier } \\
\text { otra relación de } \\
\text { hecho o amistad }\end{array}$} & $\begin{array}{l}\text { o arrojado en un } \\
\text { lugar público }\end{array}$ & \multirow{2}{*}{$\begin{array}{l}\text { el cuerpo, no es } \\
\text { posible establecer, } \\
\text { a partir de la nota, } \\
\text { si fue feminicidio, } \\
\text { homicidio o un } \\
\text { accidente. Pero el } \\
\text { manejo de la } \\
\text { imagen destaca } \\
\text { para ser analizada }\end{array}$} \\
\hline Homicidio. & & $\begin{array}{l}\text { Que presente } \\
\text { lesiones infamantes, } \\
\text { degradantes o } \\
\text { mutilaciones previos } \\
\text { a la muerte, o } \\
\text { marcas infamantes, } \\
\text { degradantes o } \\
\text { mutilaciones sobre } \\
\text { el cadáver }\end{array}$ & \\
\hline
\end{tabular}

A partir de los elementos que caracterizan a víctimas y agresores cuyas imágenes aparecen o se encuentran ausentes en las fotografías que acompañan las notas periodísticas, encontramos que

1. La presentación y exhibición de los cuerpos es diferente si de hombres o de mujeres se trata. Los cadáveres de ellas son exhibidos sin ninguna consideración a la dignidad que tuvieron (y tienen) en tanto personas. Se muestra piel, la mayor cantidad que sea posible. No importa que el cuerpo esté en avanzado estado descomposición.

Mujeres tratadas como objeto, muertas, semidesnudas, que "aprovechan una última oportunidad" para "mostrar" su ropa íntima, aderezada por la vulnerabilidad que les costó la vida. Así, este último evento en donde un cadáver "se ve obligado" a interactuar, está marcado por los clichés que se adjudican a la identidad femenina tradicional: cuestionamiento, descalificación y duda; también la exhibición burda de su cuerpo y sexualidad.

2. Presentación de lo masculino. En contraste, las imágenes asociadas al agresor respetan la dignidad de su cuerpo y su calidad de persona. Las prendas que le visten permanecen ordenadas y en su sitio. En todo caso, se exalta la agresividad y fuerza del individuo, pero sin denigrar su corporalidad, ni sexualizarla.

Se privilegia el contraste entre los cuerpos inertes de hombres y mujeres para destacar la construcción de sus diferencias y abonar a la percepción social de éstas. La víctima y el victimario. La vulnerabilidad y la fuerza.

3. De los cuerpos femeninos. Es frecuente encontrar notas periodísticas acompañadas por imágenes que muestran cadáveres desnudos o semidesnudos, con las piernas abiertas, mostrando en algunas ocasiones su ropa interior, su desnudez parcial o total. Invariablemente se trata de mujeres.

La imagen que exhibe desnudez femenina, sin importar cuál es el contexto en donde ésta se presente, ha persistido a lo largo del tiempo en la prensa y las fotografías que ahí se muestran. Fue una regla no escrita que cómodamente hizo su transición hacia los medios digitales. Cada vez más accesibles, vía páginas web y redes sociales, que son presentadas ante cualquier persona de cualquier edad que posea una computadora y acceso a portales informativos.

4. Objetivación de las mujeres. A partir del punto anterior, se observa que el concepto objeto femenino, tan utilizado en nuestra cultura, es sumamente socorrido 
en los eventos límite como es el de la muerte violenta. La mujer objeto es recreada una y otra vez a partir de la imagen que la muestra en su vulnerabilidad y decadencia.

Todo ello permite la vigencia, validez y naturalización de esta figura. Los vehículos que transmiten estos contenidos son diversos y de fácil acceso: los medios tradicionales impresos, el internet, los dispositivos tecnológicos como los teléfonos inteligentes, tableta (o tablet), entre otros.

5. Cuerpos subordinados. Las fotografías que dan cuenta de los feminicidios y homicidios de mujeres repiten la constante de concentrarse en detalles que resaltan la desventaja, vulnerabilidad y objetivación de las víctimas. Los cuerpos femeninos son desechables, parece ser el mensaje de las imágenes.

Cada nota exhibe una y otra vez, las mismas características con las que se captura la imagen del cadáver femenino. La repetición de este patrón nutre la indiferencia de quien observa y lee la noticia, naturalizando el hecho.

6. Los mensajes implícitos. El lente de quien toma la fotografía del cuerpo de una mujer al que le fue arrebatada la vida en un evento violento, constituye un mecanismo aleccionador, tanto para hombres como para mujeres. Las imágenes son tan ilustrativas como espeluznantes. Llevan el mensaje implícito de que a las mujeres se les castiga con la vida y se les exhibe como último acto sancionador. El agresor rara vez está presente, pero siempre habrá manera de justificarle con dignidad.

La violencia contra mujeres y niñas ha ocupado un espacio importante en los medios informativos, pero el hecho de nombrar el fenómeno es reciente. Ello se debe a la toma de conciencia de la sociedad sobre la gravedad de la violencia feminicida, así como el posicionamiento de los medios de comunicación al respecto (CIMAC, 2011, p. 40). Sin embargo, esta puesta en escena de la violencia misógina no se encuentra exenta de la exacerbación de ésta, abonando hacia nuevos mecanismos que actualizan y naturalizan la violencia de género.

\section{Hasta la última foto...}

La evolución de la sociedad, sus tradiciones y sus costumbres se alían con las prácticas productivas, los valores y las creencias propias de la profesión periodística, que considera natural lo que no es más que una construcción con la que periodistas, medios y público forman un sistema perfectamente sincronizado que se retroalimenta de manera continua (Bach, et al. 2000, 5).

En este texto se ha aludido a algunas imágenes que, si bien no representan en su totalidad al fotoperiodismo local, reflejan su gran impacto en los medios de comunicación y, desde luego, en el público que los consume. El efecto es diverso. Se transita del horror a la naturalización de la violencia hacia las mujeres y las niñas. La fotografía que día con día retoma la misoginia con la que se trata al suceso del feminicidio y de los asesinatos de mujeres en general, construye la percepción de la identidad de género femenina tradicional, pero también a la banalización del tema que resalta.

Es necesario destacar que las imágenes burdas y explícitas no siempre logran desencadenar la reflexión crítica de quien las observa o de quien las produce. 
También existen otras de estética y presentación en las que prevalece el manejo misógino y patriarcal.

Algunas autoras señalan que los medios de comunicación son propuestas de lectura de la realidad, en vez del reflejo de la realidad (Bach, et al. 2000, 5). Cuando esas lecturas son coherentes con el discurso social que permea a la realidad misma, se convierte en un aparato que consolida los estereotipos de género y la violencia que va implícita en ellos. En este sentido, el manejo de las noticias e imágenes sobre las mujeres víctimas de homicidio y feminicidio constituyen un gran ejemplo del manejo misógino y violento del tema, de la nota y las mujeres a las que se les victimiza a través de las imágenes que las muestran en toda su vulnerabilidad.

Los medios de comunicación son el reflejo de una sociedad que viraliza la violencia contra las mujeres, las estereotipa y pone en riesgo, que las define en tanto objetos, arrancándoles cualquier atisbo de humanidad. Hoy en día, las mujeres siguen siendo noticia fundamentalmente como sujeto negativo: como víctimas de violencias (De los Ríos y Martínez 1997, 98-99). Ojalá podamos revertir esta tendencia. Un esfuerzo de largo aliento, en donde la desnaturalización de la misoginia es la pieza fundamental.

\section{Bibliografía}

ATENCIO, Graciela. 2015. Feminicidio. El asesinato de mujeres por ser mujeres. Madrid: Fundación internacional Baltasar Garzón, Los libros de la Catarata.

BACH, Marta, Elvira Altés, Joana Gallego, Marta Plujà y Monserrat Puig. 200o. El sexo de la noticia. Reflexiones sobre el género en la información y recomendaciones de estilo. Barcelona: Icaria. http://eva.universidad.edu.uy/pluginfile.php/308222/mod_resource/conte nt/1/Bach\%20et\%20al\%20\%20EL\%20SEXO\%20DE\%20LA\%20NOTICIA\% 20-\%20Icaria\%2C\%20Barcelona\%202000.pdf [Consulta: 25 de abril de 2016].

BERLANGA GAYÓN, Mariana. 2018. Una mirada al feminicidio. México: Universidad Autónoma de la Ciudad de México, Itaca.

BUSTOS ROMERO, Olga. 2011. "Sexismo en el lenguaje: claves para erradicarlo en los medios y en las instituciones”. Comunicação Informação, Facultad de Información y comunicación, Universidade Federal de Goiás, Goiânia: 19-46. http://basessibi.c3sl.ufpr.br/brapci/index.php/article/download/44805 [Consulta: 23 de julio de 2017].

CARTIER-BRESSON, Henry. 2004. "El instante decisivo”. En Estética fotográfica. Una selección de textos, editado por Joan Fontcuberta, 221-236. Barcelona: Editorial Gustavo Gili.

CASADOS GONZÁLEZ, Estela. 2016. "Impunidad e invisibilización de los feminicidios en Veracruz". Clivajes. Revista de Ciencias Sociales (Universidad Veracruzana), núm. 6, año III, (julio-diciembre de 2016): 58-78. http://revistas.uv.mx/index.php/Clivajes/article/view/2149/3901 [Consulta: 10 de octubre 2017].

CIMAC (Comunicación e Información de la Mujer, A. C). 2011. Hacia la construcción de un periodismo no sexista. México: CIMAC/ UNESCO. 
CIDEM (Colectivo de Investigación, Desarrollo y Educación entre Mujeres, A.C.). s/f. Monitoreo de la violencia contra las mujeres y las niñas en los medios de comunicación en Veracruz. Xalapa: CIDEM.

DE BARBIERI, Teresita. 2000. "Acerca de las propuestas metodológicas feministas". En Debates en torno a una metodología feminista, compilado por Eli Bartra, 103-139. México: UNAM, UAM-X.

DE FONTCUBERTA, Mar. 1994. "Imagen, mujer y medios". En Pensar las diferencias, compilado por Mercedes Vilanova, 149-160. Barcelona: Universitat de Barcelona/ Institut Catalá de la Dona. http://www.bdigital.unal.edu.co/47756/1/8447703215.pdf [Consultado el 25 de abril de 2016].

DE LOS RÍOS PORRAS, Ma José y Joaquina Martínez Rodríguez. 1997. "La mujer en los medios de comunicación". Comunicar. Revista científica de comunicación y educación, vol. V, núm. 9, $2^{0}$ semestre, (octubre 1997): 97104.

http://www.revistacomunicar.com/index.php?contenido=detalles\&numero =9\&articulo=09-1997-14 [Consulta: 10 de abril de 2016].

Gobierno del Estado de Veracruz. 2012. Gaceta oficial, tomo CLXXXVI, núm. ext. 228 (11 de julio de 2012).

MUÑIZ, Elsa. 2013. "El género como concepto teórico crítico". Ponencia presentada en el Foro Consultivo de Ciencia y Tecnología Una mirada a la ciencia, la tecnología e innovación con perspectiva de género, (diciembre 2013). México.

LAGARDE, Marcela. 2008. "Antropología, feminismo y política: violencia feminicida y derechos humanos de las mujeres". En Retos teóricos y nuevas prácticas, coordinado por Margaret Louise Bullen y María Carmen Díez Mintegui, 209-239. Donostia: Ankulegi Antropología Elkartea.

LAGUNES HUERTA, Lucía. 2009. "Periodismo sin discriminación: reto del siglo XXI". El Cotidiano, núm. 158 (noviembre-diciembre de 2009): 87-91.

ONU. 1995. Informe de la Cuarta Conferencia Mundial sobre la Mujer. Beijin: ONU. http://www.un.org/womenwatch/daw/beijing/pdf/Beijing\%2ofull\%2orepo rt\%20S.pdf [Consulta: 27 de abril de 2016].

PULEO, Alicia H. 2007. "Introducción al concepto de género". En Género y comunicación, editado por Juan H. Plaza y Carmen Delgado, 13-32. Madrid: Fundamentos. https://books.google.es/books?id=mpurzKmHAoC\&printsec $=$ frontcover\&hl $=$ es\&source $=g b s \_g e \_s u m m a r y \_r \& c a d=0 \# v=0$ nepage\&q\&f=false [Consulta: 19 de abril de 2016].

RUSSELL, Diana y Roberta A. Harmes (Eds.). 2006. Feminicidio: una perspectiva global. México: UNAM, LIX Legislatura de la Cámara de Diputados.

SCOTT, Joan W. 1999. "El género: una categoría útil para el análisis histórico”. En El género: la construcción cultural de la diferencia sexual, compilado por Marta Lamas, 265-302. México: UNAM-PUEG/ Porrúa.

SMITH, W. Eugene (2004). "Fotoperiodismo". En Estética fotográfica. Una selección de textos, editado por Joan Fontcuberta, 209-212. Barcelona: Editorial Gustavo Gili.

VAN DIJK, Teun A. 1997. Racismo y análisis crítico de los medios. Barcelona: Paidós. 


\section{Anexo}

\section{Medios de comunicación consultados}

\begin{tabular}{|l|l|l|l|}
\hline 1. & La Opinión de Poza Rica & 22. & El Mundo de Orizaba \\
\hline 2. & Noreste & 23. & Sonríe Orizaba \\
\hline 3. & El Heraldo de Poza Rica & 24. & La Tía Justa \\
\hline 4. & Diario Martinense & 25. & Buzón Xalapa \\
\hline 5. & Noticias Papantla & 26. & El Piñero de la Cuenca \\
\hline 6. & AVI Veracruz & 27. & Milenio \\
\hline 7. & Diario de Xalapa & 28. & Gráfico de Xalapa \\
\hline 8. & Al Calor Político & 29. & Imagen Siglo XXI \\
\hline 9. & Zona Ver Noticias & 30. & El Sol de Orizaba \\
\hline 10. & El Sol de Córdoba & 31. & El Buzón de Córdoba \\
\hline 11. & La Nigua & 32. & Mega Noticias \\
\hline 12. & El Buen Tono & 33. & Diario de Acayucan \\
\hline 13. & Xalapa al momento & 34. & El Heraldo de Coatzacoalcos \\
\hline 14. & Guardián Ć́vico & 35. & Diario de Los Tuxtlas \\
\hline 15. & El Dictamen & 36. & Diario del Itsmo \\
\hline 16. & Avc Noticias & 37. & XEU Noticias \\
\hline 17. & Foto Reporte Xalapa & 38. & e-Consulta \\
\hline 18. & Notiver & 39. & Infoveracruz \\
\hline 19. & Golpe Político & 40. & Imagen del Golfo \\
\hline 20. & Escribiendo con Tinta Negra & 41. & 6o minutos \\
\hline 21. & Versiones & & \\
\hline
\end{tabular}

